\title{
Effects of a community-based healthy heart program on increasing healthy women's physical activity: a randomized controlled trial guided by Community-based Participatory Research (CBPR) Raha Pazoki, Iraj Nabipour*, Nasrin Seyednezami and Seyed Reza Imami
}

Address: Department of Healthy Heart, The Persian Gulf Health Research Center, Bushehr University of Medical Science, Bushehr, I.R. Iran Email: Raha Pazoki - pazkipg@bpums.ac.ir; Iraj Nabipour* - nabipourpg@bpums.ac.ir; Nasrin Seyednezami - Nasrin_naz2001@yahoo.com; Seyed Reza Imami - inabim@yahoo.com

* Corresponding author

Published: 23 August 2007

BMC Public Health 2007, 7:216 doi:10.1 186/147/-2458-7-216
Received: 6 December 2006

Accepted: 23 August 2007

This article is available from: http://www.biomedcentral.com/I47I-2458/7/2/6

(C) 2007 Pazoki et al; licensee BioMed Central Ltd.

This is an Open Access article distributed under the terms of the Creative Commons Attribution License (http://creativecommons.org/licenses/by/2.0), which permits unrestricted use, distribution, and reproduction in any medium, provided the original work is properly cited.

\begin{abstract}
Background: Cardiovascular disease remains the leading killer of women in most developed areas of the world. Rates of physical inactivity and poor nutrition, which are two of the most important modifiable risk factors for cardiovascular disease in women, are substantial. This study sought to examine the effectiveness of a community-based lifestyle-modification program on increasing women's physical activity in a randomized trial guided by community-based participatory research (CBPR) methods.

Methods: A total of 335 healthy, 25-64 years old women who had been selected by a multiple-stage stratified cluster random sampling method in Bushehr Port/l.R. Iran, were randomized into control and intervention groups. The intervention group completed an 8-week lifestyle modification program for increasing their physical activity, based on a revised form of Choose to Move program; an American Heart Association Physical Activity Program for Women. Audio-taped activity instructions with music and practical usage of the educational package were given to the intervention group in weekly home-visits by 53 volunteers from local non-governmental and community-based organizations.

Results: Among the participants, the percentage who reported being active (at lease 30 minutes of moderate intensity physical activity for at least 5 days a week, or at least 20 minutes of vigorous physical activity for at least three days a week) increased from $3 \%$ and $2.7 \%$ at baseline to $13.4 \%$ and $3 \%$ ( $<$ $0.000 \mathrm{I}$ ) at the ending of the program in the intervention and control groups, respectively. The participants in the intervention group reported more minutes of physical activity per week (mean $=139.8 \mathrm{I}, \mathrm{SE}=23.35)$ than women in the control group (mean $=40.14, \mathrm{SE}=12.65)$ at week $8(p<0.0001)$. The intervention group subjects exhibited a significantly greater decrease in systolic blood pressure $(-10.0 \mathrm{mmHg})$ than the control group women $(+2.0 . \mathrm{mmHg})$. The mean ranks for posttest healthy heart knowledge in the intervention and control groups were 198.91 and 135.77 , respectively $(P<0.000 \mathrm{I})$.

Conclusion: An intervention based on CBPR methods can be effective for the short-term adoption of physical activity behavior among women. The development of participatory process to support the adequate delivery of lifestyle-modification programs is feasible and an effective healthcare delivery strategy for cardiovascular community health promotion.
\end{abstract}

Trial Registration: ACTRNOI260600052I 527 


\section{Background}

Cardiovascular disease (CVD) remains the leading killer of women in most developed areas of the world. Coronary heart disease (CHD) accounts for the majority of CVD deaths in women. Because CHD is fatal, and because nearly two thirds of women who die suddenly have no previously recognized symptoms, it is essential to prevent CHD [1].

It is estimated that a woman in the United States dies of CVD every minute [2].

Public awareness of the scope of CVD and death in women is still lacking. In a recent study, only $46 \%$ of women knew that CVD was the leading cause of death in women [3].

Essentially, all CVD risk factors and the strategies for preventing them among men are also important for women. This issue, however, requires a gender lens, because the magnitude of risk factor effects may be different in men and women [4].

Lack of physical activity has been shown to be a strong independent risk factor for death from coronary heart disease. In a meta-analysis, Berlin and Coditz [5] calculated a 1.9 fold increased relative risk for CHD mortality associated with a sedentary lifestyle compared with a vigorously active lifestyle. Data also indicate that physical activity, including moderate-intensity exercise such as walking, is associated with substantial reduction in risk of total and ischemic stroke in a dose-response manner [6]. Cross-sectional studies of mid-life and older women have found associations between physical activity and a number of health-related variables, including blood pressure, highdensity lipoprotein cholesterol, obesity, anxiety, and depression [7-10]. Rates of physical inactivity and poor nutrition, which are two of the most important modifiable risk factors for CVD in women, are substantial [11], but interventional studies for reducing theses modifiable risk factors in women have been limited and often confined to experimental-settings. An experimental-setting program seems unfeasible for the general public, since lifestyle modification should be continued for a longterm. On the other hand, a community-based program is generally acceptable and feasible for all participants. Unfortunately, there are very few community-based lifestyle-modification programs on cardiovascular risk factors including physical activity in women [12-14]. To address the epidemic of physical inactivity, obesity, and poor dietary practices among American women, the American Heart Association as part of its National Women's Heart Disease and Stroke Campaign, launched the Choose to Move program, a 12-week, self-help lifestyle intervention Program [11].
The public health burden of a sedentary lifestyle emphasizes the need for interventions that can reach enough women to make a health impact on a broad, public health scale [14]. Community-based participatory research (CBPR) has been identified as a key strategy in effectively reducing health disparities in underserved communities $[15,16]$. CBPR is a collaborative, partnership approach to research that equitably involves, for example, community members, organizational representatives, and researchers in all aspects of the research process. Partners contribute their expertise and share responsibilities and ownership to increase understanding of a given phenomenon, and incorporate the knowledge gained with action to enhance the health and well-being of community members [17].

There are two studies which used CBPR to impact community health promotion in cardiovascular risk factors $[18,19]$. We conducted a randomized controlled trial, a community-based and community-driven intervention, in which women were randomly assigned to the intervention and age-matched control groups. The purpose of this study was to explore the feasibility and effectiveness of using CBPR approach for physical activity promotion in women. To the best of our knowledge, this study is the first to examine the effectiveness of a community-based lifestyle-modification program on increasing women's physical activity in a randomized controlled trial guided by CBPR methods.

\section{Methods}

\section{Engaging the community}

Twelve group sessions were conducted to find out priorities in health research in Bushehr Port. The participants were community members, academic researchers, health care providers, and policy-makers. Non-communicable diseases including cardiovascular diseases were the major concerns of the groups. The result of this need assessment, the incidence of myocardial infarction in women in Bushehr (156.61 per 100,000), and data about the prevalence of coronary artery disease risk factors were presented to members of Bushehr Province Women Commission and representatives of 26 non-governmental organizations in a meeting. They convinced the importance of intervention programs for prevention of cardiovascular diseases in Bushehr.

\section{Partnerships}

We formed a community advisory board consisting of some members of Bushehr Province Women Commission, local non-governmental organizations (NGOs), and representatives of three community-based organizations (CBOs). The advisory board was instrumental in tailoring the study to the target community. For example, they suggested that local health volunteers also be referred to as health promoters. The advisory board also reviewed train- 
ing program material, reduced the duration of intervention from 12 weeks to 8 weeks, and offered insight into the recruitment of trainers. Cultural-appropriateness, readability, and comprehension of the educational material were discussed in the advisory board.

The recommendations of the advisory board were shared by health-related CBOs and academic researchers in Bushehr University of Medical Science. Publicity concerning the study appeared in the local newspapers and on TV.

\section{Training volunteer trainers}

We used train-the-trainer approach, as a mandatory component of the program. Thus, a healthy heart trainer group consisting of 53 volunteers from local health volunteers, the members of the Persian Gulf Women Organization (as an NGO), and two CBOs were recruited. The healthy heart trainer group (HHTG) was not given a salary. They were offered four healthy heart workshops by the staffs of the Persian Gulf Health Research Center in collaboration with Bushehr Province Health Affairs.

The Persian Gulf Health Research Center and the community advisory board developed the educational curriculum. The training activities involved the development of participatory process and capacity building to support the adequate delivery of the interventions. Each member of HHTG was responsible for training five women in the intervention group. HHTG was supervised by six community members of the advisory board (as leaders), so that the advisory board would regularly stay in contact with the group. These leaders and HHTG met on a weekly basis to deepen their involvement in the intervention process. The researchers were also in close contact with the leaders.

\section{Community Sampling}

In phase I of the study, a multiple-stage stratified cluster random sampling technique was used to select women aged 25-65 years from Bushehr Port. The estimated sample size $(\mathrm{E} / \mathrm{S}=0.4$, two-sided alpha $=0.01 \&$ beta $=0.10)$ per group (intervention $\&$ control) was 188 subjects. The selected women were informed about the study through a letter given door-to-door by the survey groups. After a primary education about cardiovascular disease and its associated risk factors, they were invited to participate in the screening program in a 12-14 fasting state in the following morning to the Persian Gulf Health Research Center.

The screening program, as presented below, was consisted for diabetes, hyperlipidemia, and ischemic heart disease. Those women who had not history or evidence of angina pectoris, myocardial infarction, cerebral stroke, renal disease, severe arthritis, lung disease, or drug consumption were randomized into control and intervention groups.

\section{Intervention}

The intervention program was designed to permit women to easily incorporate physical activity and healthy eating changes into their lifestyle.

The subjects of interventional group were invited to the Persian Gulf Health Research Center; a detailed program material and four easy-to-read booklets consisting material about cardiovascular diseases, risk factors of coronary artery disease, smoking and nutrition for healthy heart were given to them.

A program for increasing physical activity (Exercise for Healthy Heart, EHH) was designed to teach women how to incorporate a daily routine of physical activity into their lives in creative and practical ways, based on Choose to Move(CTM) program; an American Heart Association Physical Activity Program for Women [11]. Choose to Move was developed to help women in the contemplative and preparatory stages of physical activity move to the next stage. Participants are asked to begin with 10 minutes per day of moderate-intensity physical activity; women are encouraged to do 30 minutes of physical activity daily. The 8-week EHH was a fully revised form of Choose to Move program.

EHH booklets including audio-taped activity instructions with music and practical usage of the educational package were given to the intervention group by members of HHTG. Each trainer covered five subjects in the intervention group. The members of HHTG met the participants in a weekly schedule. They delivered EHH educational packages in their face-to-face weekly home-visits. Each participant had a total of eight 1.5-hour face-to-face educational interview sessions with her trainer. As previously mentioned, the trainers were community members who were offered four workshops for training in healthy lifestyle including the package of EHH.

\section{Measurements}

On arrival at the survey site, information on their age, sex, marital status, education, smoking, estrogen, and drugs for angina, hypertension, diabetes, and dyslipidemia were recorded using WHO MONICA questionnaire [20] by trained interviewers. To evaluate physical activity behavior at both registration time and week 8, participants complete a 7-Day physical activity recall questionnaire based on the BRFSS; USA/CDC, 2002) and the Countrywide Integrated Non-communicable Diseases Intervention (CINID) program questionnaire [20,21]. Participants were classified as active at the recommended level if they reported sufficient physical activities of moderate intensity (i.e., $>$ or $=30$ minutes per day, $>$ or $=5$ days per week) or of vigorous intensity (i.e., $>$ or $=20$ minutes per day, $>$ or $=3$ days per week) [22]. Blood pressure was assessed 
twice at the right arm after a 15-min rest in the sitting position, using a standard mercury sphygmomanometer. Height and weight were measured using a stadiometer. Heavy outer garments and shoes were removed before measuring height and weight. Body Mass Index (BMI) was calculated. Waist circumference was defined at the midway level between the costal margins and the iliac crests. Hip circumference was measured at the level of the greater trochanters. A resting 12-lead electrocardiogram was performed.

A fasting blood sample was taken, all samples were promptly centrifuged, separated and analyses were carried out at the Persian Gulf Health Research Center on the day of blood collection using a Selectra 2 auto analyzer (Vital Scientific, Spankeren, The Netherlands). Glucose was assayed by enzymatic (glucose oxidize) colorimetric method using a commercial kit (Pars Azmun Inc; Tehran, Iran). Serum total cholesterol was measured using a cholesterol oxidase phenol aminoantipyrine and triglycerides using a glycerol-3 phosphate oxidize phenol aminoantipyrine enzymatic method.

The research team developed a questionnaire to identify the participants' healthy heart knowledge and awareness. The 49-item questionnaire was consisted of 29 nutrition items, 10 physical activity items, 8 smoking items, and 2 general items regarding healthy heart.

\section{Ethics \& Statistical analysis}

All of the subjects received detailed information regarding the purpose and nature of the study, and gave their informed consent before enrollment. This study was approved by the Ethics Committee in Bushehr University of Medical Sciences.

We used $\mathrm{x} 2$ tests to compare differences in proportions, unpaired t tests for continuous normally distributed variables, and Mann-Whitney tests for normally distributed variables (healthy heart knowledge score).

A value of $\mathrm{P}<0.05$ was established as statistically significant. Statistical analysis was performed with an IBM computer using the SPSS 10 statistical software package (SPSS Inc., Chicago, IL).

\section{Results}

Of the 589 women surveyed, 109 subjects who had history or evidence of angina pectoris, myocardial infarction, cerebral stroke, renal disease, severe arthritis, lung disease, or drug consumption were excluded. Of 480 women who remained, 385 subjects agreed to participate in the trial. They were randomly entered in the intervention group (179 cases) or the control group (179 cases). A total of 170 subjects in the intervention group completed 8-week program. They were compared with 165 age-matched women in the control group who returned for the required measurements in the second session. The subjects ranged in age from 25 to 64 years (mean age, 39.4 years).

There were no significant differences in baseline demographic characteristics of the intervention and control groups; including socioeconomic status data.

The characteristics of the two groups at baseline and after 8 -week program were summarized in Table 1 . At baseline, there was no significant body mass Index (BMI), waist to hip ratio, systolic and diastolic blood pressures, fasting blood sugar, lipid profile and physical activity levels differences between the study groups.

Among the participants, the percentage of those who reported being active increased from 3.0\% and 2.5\% at baseline to $13.4 \%$ and $3.0 \%(\mathrm{p}<0.0001)$ at the program end in the intervention and control groups, respectively. There were statistically significant differences between the two groups in regard to changes in moderate $(\mathrm{p}=0.03)$ and vigorous $(\mathrm{p}=0.001)$ physical activities (Table 1$)$. We found that participants in the intervention group reported more minutes of physical activity per week (mean = 139.81, $\mathrm{SE}=23.35$ ) than women in the control group $($ mean $=40.14, \mathrm{SE}=12.65)$ at week $8(\mathrm{p}<0.0001)$.

As shown in Table 1, there were no significant differences between the groups with regard to BMI, WHR, serum sugar and lipid levels, and diastolic blood pressure changes from baseline. However, the intervention group subjects exhibited a significantly greater decrease in systolic blood pressure $(-10.0 \mathrm{mmHg})$ than the control group women (+2.0 $\mathrm{mmHg})$.

Total heart-healthy awareness and knowledge score at posttest was $6.26 \%$ higher in the intervention than in control subjects.

The mean ranks for posttest healthy heart knowledge in the intervention and control groups were 198.91 and 135.77 , respectively $(\mathrm{U}=8736.5 \mathrm{P}<0.0001)$.

\section{Discussion}

Results indicated that participants in the intervention group spent significantly more minutes of physical activity (of at least moderate intensity) comparing to participants of the control group in 8 weeks. The study demonstrated that volunteers could be successfully trained to deliver an educational program designed to increase physical activity in women. Furthermore, volunteers of the Healthy Heart Trainer Group were able to effectively recruit members of their community through 
Table I: Physical and clinical characteristics and healthy heart knowledge of the subjects before and after 8-week program for intervention and control groups

\begin{tabular}{|c|c|c|c|c|c|}
\hline & \multicolumn{2}{|c|}{ Intervention } & \multicolumn{2}{|c|}{ control } & \multirow[b]{2}{*}{$P$ value } \\
\hline & Before & After & Before & After & \\
\hline $\begin{array}{l}\text { Body Mass Index }(\mathrm{kg} / \\
\left.\mathrm{m}^{2}\right)\end{array}$ & $28.02(4.74) \S$ & $27.53(4.49)$ & $27.82(5.39)$ & $28.05(8.42)$ & NS \\
\hline waist to hip ratio $(\mathrm{cm})$ & $0.91(0.06)$ & $0.87(0.07)$ & $0.92(0.07)$ & $0.88(0.07)$ & NS \\
\hline $\begin{array}{l}\text { Systolic blood } \\
\text { pressure (mmhg) }\end{array}$ & $111.28(14.47)$ & $110.28(17.17)$ & $111.38(13.40)$ & $113.60(12.64)$ & 0.04 \\
\hline $\begin{array}{l}\text { Diastolic blood } \\
\text { pressure(mmhg) }\end{array}$ & $68.97(12.11)$ & $72.62(9.95)$ & $69.95(11.26)$ & $74.19(8.87)$ & NS \\
\hline $\begin{array}{l}\text { Total cholesterol(mg/ } \\
\text { dl) }\end{array}$ & $193.15(37.94)$ & 196.88(40.38) & $199.15(40.14)$ & $200.82(42.18)$ & NS \\
\hline Triglyceride (mg/dl) & $127.66(74.84)$ & I33.38(73.94) & $130.23(69.11)$ & $|40.2|(73.77)$ & NS \\
\hline $\begin{array}{l}\text { Fasting Blood Sugar } \\
(\mathrm{mg} / \mathrm{dl})\end{array}$ & $81.94(14.46)$ & $86.65(12.58)$ & $83.5 I(\mid 8.80)$ & $87.54(\mid 4.77)$ & NS \\
\hline $\begin{array}{l}\text { Knowledge Score (out } \\
\text { of 49) }\end{array}$ & & $41.12(0.26)$ & & $38.01(0.39)$ & $<0.0001$ \\
\hline $\begin{array}{l}\text { Moderate physical } \\
\text { activity (minutes/ } \\
\text { week) }\end{array}$ & $17.59(5.23)$ & $116.46(18.03)$ & $26.59(11.61)$ & $37.15(12.42)$ & 0.03 \\
\hline $\begin{array}{l}\text { Vigorous physical } \\
\text { activity (minutes/ } \\
\text { week) }\end{array}$ & $4.09(1.81)$ & $21.38(8.70)$ & $3.61(1.65)$ & $3.02(1.03)$ & 0.001 \\
\hline
\end{tabular}

$\S$ Values are mean (SD), except for physical activity and knowledge score which are mean (SE)

the usage of their social networks, to conduct the healthpromotion program.

Chose to Move (CTM) program was designed to be delivered in a self-help format, without in-person supplementation; it was mainly a mail-mediated lifestyle intervention program [11]. However, our study educational material was based on a revised CTM program but we added component of in-person contact with lay health educators. In a CBPR approach, we used community volunteers to deliver healthy heart physical activity packages to women. Our program was provided a low cost intervention, enrolled a large number of women, and had a high rate of success for those who completed it. This program produced a feasible, effective, and appropriate model for low to mid-income countries. This program also showed that a social marketing approach - promoting a targeted, self-help lifestyle intervention program, designed to increase physical activity, for healthy heart can reach a large number of women and help them to positively change their behavior within 8 weeks.

With the shift in emphasis towards population level interventions to change health risk behaviors, community based participatory intervention programs such as the Persian Gulf EHH program have great appeal. These results compare favorably with other self monitoring interventions that are tailored to women's needs, in cardiovascular healthy lifestyles $[18,19]$. Participatory research methods were used to design an outreach program through a col- laborative partnership between UCLA School of Nursing, Los Angeles County Department of Health Services, and members of one community of underserved Latinos; the findings of this study supported the feasibility and effectiveness of using Lay Health Advisors for cardiovascular health promotion in a low-income community [18].

The para Su Corazon (Health for Your Heart), a community-based outreach program among Latinos, established by the National Heart, Lung, and Blood Institute partnered with the National Council of La Raza, also worked well in seven pilot programs because of the successes of the community health workers and the support of the community based organizations [19].

We implemented many elements of CBPR in EHH program, with community members engaged early in the process and throughout the project. We formed a community advisory board consisting of some members of Bushehr Province Women Commission, local NGOs, and representatives of three CBOs. Through meetings, and frequent subcommittee meetings, the university researchers and the members of community began to understand and respect each other's expertise and respective. The study team relied on input from members of the community to guide the nature and structure of the intervention. The rationale for pursuing community participation includes promoting positive health behavioral change; improving service delivery; mobilizing human, financial and other material(including in-kind) resources for health services; 
and as a means of empowering the community [23]. CBPR motivates co-learning and sharing expertise by researchers and community members [17]. It differed from more traditional community-based research, which favors work conducted in a community setting, but with limited community involvement [24].

The employment of a CBPR approach in our research enhanced the design, conduct, and conclusions of our study. Our inclusion of program partners in the interpretation of study findings led to more dynamic modes of analysis and more reflective conclusion drawing processes that also proved useful for program and community development.

In summary, the current findings support the use of community-based approach as a feasible and effective healthcare delivery strategy for community health promotion at a grassroots level, and as having promising indicators of sustainability over time. Sustainability is an important issue for community-based health-promotion interventions to make a difference over time. Some studies have suggested correlates of sustainability in terms of intervention characteristics, such as interventions that use no paid staff $[25,26]$.

The EHH team including the community members were not paid a salary. However, it is too soon to determine whether we have been successful in creating a sustainable cadre of community-based expert trainers for healthy heart.

There were a number of strengths of this study. The first published evaluation of a CTM program was a quasiexperimental, non-randomized study of the 1999 version [11]. Survey results indicated women increased their activity, but there was high attrition and a lack of comparison groups [11]. For the first time, Napolitano et al [14] designed a controlled trial which compared CTM printbased program to another print-based physical activity promotion program (i.e., Jumpstart) and a Wellness contact control group. Our study was the second one which examined the efficacy of the American Heart Association's Choose to Move (CTM) program for physical activity promotion delivered via in-person home visits in comparison to a control group. Napolitano et al [14] and our study provided the first controlled comparison of AHA materials which may provide information for the AHA in the design and dissemination of future programs.

The EHH program participants were free of cardiovascular disease who selected in general population, irrespective to their baseline cardiovascular risk factors. Individuals who already have one or more mild cardiovascular risk factors still could be good candidates for a community-based par- ticipatory lifestyle-modification program. A communitybased lifestyle-modification program that consisted of mild aerobic exercise and a mild hypo caloric diet was considered to be practically effective for reducing multiple cardiovascular risk factors [13].

For feasibility, our study used self-reported data for physical activity behavior, a limitation for validating results. A prospective study by Blair et al, however, found that selfreported physical activity was the predominant predictive factor of cardio respiratory fitness among adults in all age and sex subgroups they analyzed [27]. In addition, the questions that measured physical activity have been field tested and are used in the BRFSS; USA/CDC, 2002) and the Countrywide Integrated Non-communicable Diseases Intervention (CINID) program [20,21]. Future studies should include some measure of fitness of women in the community, such as a 2-km walking test or the Rockport Walking Test for field settings [28].

In two American studies, high HDL-C levels in women have been shown to be important in providing a protective effect from coronary heart disease [29]. Several cohort studies found that increases in physical activity were associated with favorable changes in HDL-C $[30,31]$. However, exercise intervention studies have not demonstrated consistently an improvement in women's lipid and lipoprotein profiles [32]. In EHH program, no statistically significant decrease in lipid levels corresponding to a change in physical activity was found; it may reflect the lack of sufficient change in exercise behavior or limited power of the study to detect small effects in short terms. Total of awareness, knowledge, and perceptions about heart disease, and healthy heart lifestyle was $6.26 \%$ correct higher in the intervention than in the control group. It seems that EHH program succeeded at improving heart-health awareness and creating a cultural environment for learning heart-health information to promote changes in lifestyle behaviors among women of the intervention group.

In this work, we found that CBPR is an important research approach in addressing cardiovascular prevention among women. It is compatible with cultural values. Continued effort needs to be directed towards creating systems and structures to support researchers in utilizing this method.

In conclusion, it is possible to deliver heart-healthy program through existing community infrastructures. This program provides an important model for public health, voluntary, and other health organizations of populationbased, targeted low cost self-help programs that support objectives for physical activity and cardiovascular health. 


\section{Conclusion}

An intervention based on CBPR methods can be effective for the short-term adoption of physical activity behavior among women. The development of participatory process to support the adequate delivery of lifestyle-modification programs is feasible and an effective healthcare delivery strategy for cardiovascular community health promotion.

\section{Competing interests}

The author(s) declare that they have no competing interests.

\section{Authors' contributions}

$\mathrm{RP}$ and IN had conceived and designed the study as well as wrote the manuscript; NS and SRI assisted in the field survey. All authors read and approved the final manuscript.

\section{Acknowledgements}

We wish to thank volunteers of NGOs and CBOs in Bushehr Port who participated in this study and staff of Bushehr Port Health Affairs for their kind assistance. We are indebated to Seyed Mojtaba Jafari, Zahra Sanjdideh, Zarah Amiri, Shiva Mosadeghzadeh, Behnoush Bonegazi, Fatemeh Marzoghi, Azam Tavanimoghadam and Taminh Sarkari for coordinating the collection of samples and for laboratory management.

This study was supported in part by a grant from Bushehr Province Technology and Research Committee and Research Deputy of Bushehr University of Medical Science.

\section{References}

I. Mosca L, Appel LJ, Benjamin EJ, Berra K, Chandra-Strobos N, Fabunmi RP, Grady D, Haan CK, Hayes SN, Judelson DR, Keenan NL, McBride P, Oparil S, Ouyang P, Oz MC, Mendelsohn ME, Pasternak RC, Pinn VW, Robertson RM, Schenck-Gustafsson K, Sila GA, Smith SC, Sopko G, Taylor AL, Walsh BW, Wenger NK, Williams CL, AHA: Evidence-based guidelines for cardiovascular disease prevention in women. Circulation 2004, 109:672-693.

2. Holcomb SS: Prevent cardiovascular disease in women. Nurse Pract 2004, 29:6-II.

3. Mosca L, Ferris A, Fabunmi R, Robertson RM: Tracking women's awareness of heart disease: an American Heart Association national study. Circulation 2004, 109:573-579.

4. Oda E, Abe M, Kato K, Watanabe K, Veeraveedu PT, Aizawa Y: Gender differences in correlations among cardiovascular risk factors. Gend Med 2006, 3:196-205.

5. Berlin JA, Colditz G: A meta-analysis of physical activity in the prevention of coronary heart disease. Am J Epidemiol 1990, 132:612-628.

6. Mosca L, Jones WK, King KB, Ouyang P, Redberg RF, Hill MN: Awareness, perception, and knowledge of heart disease risk and prevention among women in the United States. American Heart Association Women's Heart Disease and Stroke Campaign Task Force. Arch Fam Med 2000, 9:506-5I5.

7. Reaven PD, Barrett-Connor E, Edelstein S: Relation between leisure-time physical activity and blood pressure in older women. Circulation 1991, 83:559-65.

8. Cauley JA, La Porte RE, Sandler RB, Orchard TJ, Slemenda CW, Petrini AM: The relationship of physical activity to high density lipoprotein cholesterol in postmenopausal women. J Chronic Dis 1986, 39:687-697.

9. Owens JF, Matthews KA, Wing RR, Kuller LH: Physical activity and cardiovascular risk: a cross-sectional study of middle-aged premenopausal women. Prev Med 1990, 19:147-157.
10. Stephens T: Physical activity and mental health in the United States and Canada: evidence from four population surveys. Prev Med 1988, 17:35-47.

II. Koffman DM, Bazzarre T, Mosca L, Redberg R, Schmid T, Wattigney WA: An evaluation of Choose to Move 1999: an American Heart Association physical activity program for women. Arch Intern Med 200I, 16I:2193-2199.

12. Guthrie JR, Dudley EC, Dennerstein L, Hopper JL: Changes in physical activity and health outcomes in a population-based cohort of mid-life Australian-born women. Aust $N Z$ J Public Health 1997, $21: 682-687$.

13. Okazaki T, Himeno E, Nanri H, Ikeda M: Effects of a communitybased lifestyle-modification program on cardiovascular risk factors in middle-aged women. Hypertens Res 200I, 24:647-653.

14. Napolitano MA, Whiteley JA, Papandonatos G, Dutton G, Farrell NC, Albrecht A, Bock B, Bazzarre T, Sciamanna C, Dunn AL, Marcus BH: Outcomes from the women's wellness project: A community-focused physical activity trial for women. Prev Med 2006, 43:447-53.

15. Baker EL, White LE, Lichtveld MY: Reducing health disparities through community-based research. Public Health Rep 200I, I 16:517-9.

16. Flaskerud $\mathrm{JH}$ : Keynote: Building excellence and scholarship with vulnerable population. The 35th communicating Nursing Research Conference Proceedings, Western Institute of Nursing; Palm Spring, Calif 2002.

17. Israel BA, Schulz AJ, Parker EA, Becker AB: Community-Campus Partnerships for Health. Community-based participatory research: policy recommendations for promoting a partnership approach in health research. Educ Health (Abingdon) 200I, 14:182-197.

18. Kim S, Koniak-Griffin D, Flaskerud JH, Guarnero P: The impact of lay health advisors on cardiovascular health promotion: using a community-based participatory approach. J Cardiovasc Nurs 2004, 19:192-199.

19. Balcazar H, Alvarado M, Hollen ML, Gonzalez-Cruz Y, Pedregon V: Evaluation of Salud Para Su Corazon (Health for your Heart) - National Council of La Raza Promotora Outreach Program. Prev Chronic Dis 2005, 2:A09. Epub 2005 Jun 15

20. Prineas RJ, Crowe RS, Blackburn H: The Minnesota Code manual of electrocardiographic findings. Bristol: John Wright; 1982.

21. Choudhury SR, Yoshida Y, Kita Y, Nozaki A: Association between electrocardiographic ischemic abnormalities and ischemic heart disease risk factors in a Japanese population. J Human Hypertension 1996, 10(4):225-234.

22. Sattar N, Gaw A, Scherbakova O, Ford I, O'Reilly DS, Haffner SM, Isles C, Macfarlane PW, Packard C], Cobbe SM, Shepherd J: Metabolic syndrome with and without C-reactive protein as a predictor of heart disease and diabetes in the West of Scotland Coronary Prevention Study. Circulation 2003, 108:414-419.

23. Woelk GB: Cultural and structural influences in the creation of and participation in community health programmes. Soc Sci Med 1992, 35:419-424.

24. Jacobs B, Price $\mathrm{N}$ : Community participation in externally funded health projects: lessons from Cambodia. Health Policy Plan 2003, 18:399-410

25. Baker EA, Bouldin N, Durham M, Lowell ME, Gonzalez M, Jodaitis N, Cruz LN, Torres I, Torres M, Adams ST: The Latino Health Advocacy Program: a collaborative lay health advisor approach. Health Educ Behav 1997, 24:495-509.

26. O'Loughlin J, Renaud L, Richard L, Gomez LS, Paradis G: Correlates of the sustainability of community-based heart health promotion interventions. Prev Med 1998, 27:702-7I 2.

27. Blair SN, Kohl HW 3rd, Paffenbarger RS Jr, Clark DG, Cooper KH, Gibbons LW: Physical fitness and all-cause mortality. A prospective study of healthy men and women. JAMA 1989, 262:2395-2401.

28. American College of Sports Medicine, 2000. In ACSM's Guidelines for Exercise Testing and Prescription Edited by: Franklin BA, Whaley MH, Howley ET. Lippincott, Williams \& Wilkins, Philadelphia, PA; 2000.

29. Gordon DJ, Probstfield JL, Garrison RJ, Neaton JD, Castelli WP, Knoke JD, Jacobs DR, Bangdiwala S, Tyroler HA: High-density lipoprotein cholesterol and cardiovascular disease. Four prospective American studies. Circulation 1989, 79:8-15. 
30. Owens JF, Matthews KA, Wing RR, Kuller LH: Can physical activity mitigate the effects of aging in middle-aged women? Circulation 1992, 85: 1265-I270.

31. Young DR, Haskell WL, Jatulis DE, Fortmann SP: Associations between changes in physical activity and risk factors for coronary heart disease in a community-based sample of men and women: the Stanford Five-City Project. Am J Epidemiol 1993, 138:205-216.

32. Haskell WL: Exercise-induced changes in plasma lipids and lipoproteins. Prev Med 1984, 13:23-36.

\section{Pre-publication history}

The pre-publication history for this paper can be accessed here:

http://www.biomedcentral.com/1471-2458/7/216/pre pub

Publish with Bio Med Central and every scientist can read your work free of charge

"BioMed Central will be the most significant development for disseminating the results of biomedical research in our lifetime. "

Sir Paul Nurse, Cancer Research UK

Your research papers will be:

- available free of charge to the entire biomedical community

- peer reviewed and published immediately upon acceptance

- cited in PubMed and archived on PubMed Central

- yours - you keep the copyright

Submit your manuscript here:

http://www.biomedcentral.com/info/publishing_adv.asp 